\title{
SELECTIVITY AND CAUSES OF BACKGROUND EXTINCTIONS: EXAMPLES FROM THE LOWER PALEOZOIC
}

\author{
PATZKOWSKY, Mark E., Department of Geosciences, Pennsylvania State University, \\ University Park, PA 16802-2714, U.S.A.
}

The traditional view of extinction over geologic time recognizes two modes of extinction, mass and background extinction. Mass extinctions cause major reorganizations of the global biosphere by eliminating many successful clades while some survivors undergo massive diversification during rebounds, radically changing the composition of the global biota. Background extinctions help to shape clade histories between mass extinctions and are responsible for long-term evolutionary trends. The five major mass extinctions of the Phanerozoic have dominated extinction studies even though they constitute only a small portion (ca. 5\%) of total Phanerozoic extinctions. In contrast, background extinctions account for about $95 \%$ of Phanerozoic extinctions, yet have received much less attention from the scientific community. The emerging paradigm of Phanerozoic extinctions now suggests that extinctions are pulsed at all scales of intensity and that mass and background extinctions grade one into the other. The causes of background extinctions and the patterns of selectivity associated with them are fruitful areas for research which must be addressed for a more complete understanding of the role of extinction in evolution.

The prolonged diversification of marine animals during the Cambrian and Ordovician provides an ideal situation to analyze the biotic effects of background extinction. A number of extinctions of varying intensities and geographic extents (e.g., Cambrian biomeres, mid-Arenigian, mid-Caradocian) occur during this time period. Moreover, several recent studies indicate that these extinctions may all have similar causes: all appear to be caused by habitat destruction associated with the oceanographic changes (e.g., influx of siliciclastics, change in ocean circulation, spread of anoxic waters) associated with fluctuations in sea level. The occurrence of repeated extinctions with similar causes provides the opportunity to look for common biologic patterns among these various extinctions.

Here I compare two well-documented North American extinctions: an end-Cambrian extinction of trilobites (Westrop and Ludvigsen, 1987) and a middle Ordovician (middle Caradocian) extinction of articulate brachiopods. Initial comparisons of extinction selectivity based on habitat occurrence and environmental breadth indicate that the two events resulted in strikingly different patterns of extinction and survival. With respect to habitat occurrence, Late Cambrian trilobite extinctions were significantly higher in midshelf environments compared to deeper water settings, whereas extinctions among middle Caradocian brachiopods showed no significant difference in extinction intensity across the spectrum of environments from nearshore to deep basin. As for environmental breadth, Late Cambrian trilobites showed no difference in extinction magnitude based on the number of biofacies occupied, whereas rare and stenotopic brachiopods were eliminated preferentially in the middle Caradocian. The source of these differences in extinction selectivity is currently unclear. The differences may reflect the response of ecologically distinct clades to similar environmental perturbations. Alternatively, the differences in extinction selectivity may indicate a real difference in extinction mechanism between the two time periods that is currently not understood. These hypotheses can be evaluated in part by looking at the patterns of extinction in trilobites in the middle Caradocian thereby controlling for clade membership; articulate brachiopods were not diverse enough in the Cambrian to make the complementary test. Preliminary data suggest that middle Caradocian trilobites show patterns of extinction similar to the middle Caradocian brachiopods and not similar to the Cambrian trilobites. This lends support to the idea of different extinction mechanisms operating during the two intervals. 